\title{
THE CALIFORNIA COOPERATIVE OCEANIC FISHERIES INVESTIGATIONS (CALCOFI): THE CONTINUING EVOLUTION AND CONTRIBUTIONS OF A 60-YEAR OCEAN OBSERVATION PROGRAM
}

\author{
J. Anthony Koslow ${ }^{(1)}$, Ralf Goericke ${ }^{(1)}$, Sam McClatchie ${ }^{(2)}$, Russ Vetter ${ }^{(2)}$, Laura Rogers-Bennett $^{(3)}$ \\ (1) Scripps Institution of Oceanography, University of California, San Diego, 9500 Gilman Dr, 92093-0218 \\ La Jolla, CA USA, Email: tkoslow@ucsd.edu; rgoericke@ucsd.edu \\ (2) Southwest Fisheries Science Center, National Marine Fisheries Service/NOAA (National Oceanic and Atmospheric \\ Administration), 8604 La Jolla Shores Drive, La Jolla, CA 92037 USA, \\ Email: Sam.McClatchie@noaa.gov; Russ.Vetter@noaa.gov \\ (3) California Department of Fish and Game, Bodega Marine Laboratory, Bodega Bay, CA 94923 USA, \\ Email: rogersbennett@ucdavis.edu
}

\begin{abstract}
The California Cooperative Oceanic Fisheries Investigations (CalCOFI) began in 1949 as an ocean observation program in response to the decline of the Pacific sardine fishery. The program, based on a partnership between the National Marine Fisheries Service, California Department of Fish and Game, and the Scripps Institution of Oceanography, has served to underpin the stock assessment of key commercial species, such as northern anchovy and Pacific sardine, based on the egg production method, and has provided a primary data source for studies of the physical, biological and fisheries oceanography of the California Current in relation to ocean climate variability and climate change. The range and frequency of CalCOFI sampling has shrunk considerably since its inception, but the program continues to expand its suite of ocean observations, by serving as a sampling platform for ancillary programs and through leveraging of its observations. Results from the CalCOFI program show the tight relationships between environmental forcing and biological/fisheries productivity over a range of temporal and spatial scales. Today it stands as one of the world's longest oceanographic time series and is poised to contribute to studies of climate change and to ecosystem-based management of the California Current.
\end{abstract}

\section{INTRODUCTION TO CALCOFI}

The California Cooperative Oceanic Fisheries Investigations (CalCOFI) ocean observing program was established in 1949 in response to the decline of the Pacific sardine fishery, once the largest fishery in the western hemisphere. From its inception, CalCOFI has been a partnership between federal and state fisheries agencies, today the National Marine Fisheries Service (NMFS) and the California Department of Fish and Game, and the Scripps Institution of Oceanography. As a result of this unique partnership, CalCOFI was designed to be directly relevant to fisheries management, as well as to provide a broad scientific understanding of the physical, chemical and biological oceanography and their influence on the living marine resources of the California Current. This vision was set out in the program's first progress report in 1950:

[to] investigate the sardine in relation to its physical and chemical environment, its food supply, its predators and its competitors, in attempting to evaluate the findings in terms of the survival of the young, and in terms of the distribution and availability of the sardines when they reach commercial size.

CalCOFI today looks at a broader range of species, but this vision is as relevant today as it was then.

Because of its broad aims and the varying interests of its several partners, CalCOFI has always measured a range of oceanographic and fishery-relevant variables. The core variables include temperature, salinity, nutrients, and chlorophyll $a$ through the water column, along with net sampling of zoo- and ichthyoplankton. This suite of variables has steadily expanded, evolving along with the underlying oceanographic science and sampling technology. However, because support for the program has declined over time, expanded sampling has come about through partnerships with additional institutions, investigators and scientific programs, who leverage the CalCOFI observations with their own: seabird observations through the Pt. Reyes Bird Observatory and Farallon Institute, marine mammal observations by John Hildebrand's group at Scripps with funding from the Office of Naval Research, augmented nearshore sampling in conjunction with the Southern California Coastal Ocean Observing System (SCCOOS), and a suite of measurements undertaken by investigators associated with the NSF (National Science Foundation)-funded California Current Ecosystem Long-Term Ecological Research (CCE-LTER) study (Tab. 1).

A further defining characteristic of CalCOFI has been its sampling design, a series of onshore-offshore 


\begin{tabular}{|l|l|l|}
\hline Variable & Investigator/Program & Method \\
\hline $\begin{array}{l}\text { Temperature, salinity, Chl } a \\
\text { fluorescence }\end{array}$ & CalCOFI & CTD, fluorometer \\
\hline Irradiance (in situ profiles \& daily PAR) & CalCOFI & PAR \\
\hline Light transmission @ 660 nm & CalCOFI & Transmissometer \\
\hline Oxygen & CalCOFI & Auto-Winckler, CTD \\
\hline Nutrients (N, P, Si) & CalCOFI & Auto analyzer, CTD \\
\hline Primary production & CalCOFI & C-14 uptake \\
\hline Chl $a$ extracted & CalCOFI & Fluorometer \\
\hline Sea surface pCO2 & CalCOFI & IR absorbance \\
\hline Zooplankton, ichythyoplankton & CalCOFI & Bongo net tows \\
\hline Particulate C\&N & CCE LTER & Dry combustion \\
\hline Dissolved organics (DOC, DON) & CCE LTER & Combustion \\
\hline Upper ocean currents & Chereskin/CCE LTER & ADCP \\
\hline Taxon-specific pigments & CCE LTER & HPLC \\
\hline Bacteria \& picoautotrophs & CCE LTER & Flow cytometry \\
\hline Nano- \& microplankton & CCE LTER & Microscopy, FlowCAM \\
\hline Mesozooplankton, optical size classes & CCE LTER & OPC, LOPC \\
\hline Mesozooplankton, sentinel species & CCE LTER & Microscopy, ZOOSCAN \\
\hline Acoustics: krill, micronekton, pelagics & Koslow & Multi-frequency EK-60 \\
\hline Seabirds & Pt Reyes Bird Observatory/Farallon & Observer \\
\hline Marine mammals & Institute & \\
\hline & Hildebrand & Observers, passive acoustics \\
\hline
\end{tabular}

Table 1. Variables routinely measured on CalCOFI cruises. The period of observation varies: temperature, salinity, oxygen, zoo/ichthyoplankton in 1949, other CalCOFI measurements 1984; CCE LTER, marine mammals: 2004; acoustics: 2009. Data methods and access to the data are available at: $\underline{w w w . c a l c o f i . o r g}$.

transects that originally covered much of the California Current from north of California to the southern tip of Baja California, designed to survey the extent of the Pacific sardine population and its spawning distribution. Since 1984, the survey has contracted to the region from north of Pt Conception to the USMexico border, focusing on the Southern California Bight and southern California Current (Fig. 1), the core region for the spawning of Pacific hake and northern anchovy, as well as the sardine. Sampling was originally monthly but since 1984 has been quarterly.

Over the last two decades, several additional observing programs have been initiated in the California Current that reoccupy parts of the historical CalCOFI station pattern, providing a broader perspective on the oceanography of the California Current. Since 1997, the waters off Baja California have been surveyed quarterly along CalCOFI lines 100 to 133 by the Investigaciones Mexicanas de la Corriente de California (IMECOCAL). Several stations are occupied bi-weekly along a cross-shelf transect off Newport, Oregon, focusing on the physical and biological oceanography, including the zooplankton, which have elucidated the distinct response of the zooplankton to climate in the northern California Current [1]. CalCOFI line 67 off Monterey has been

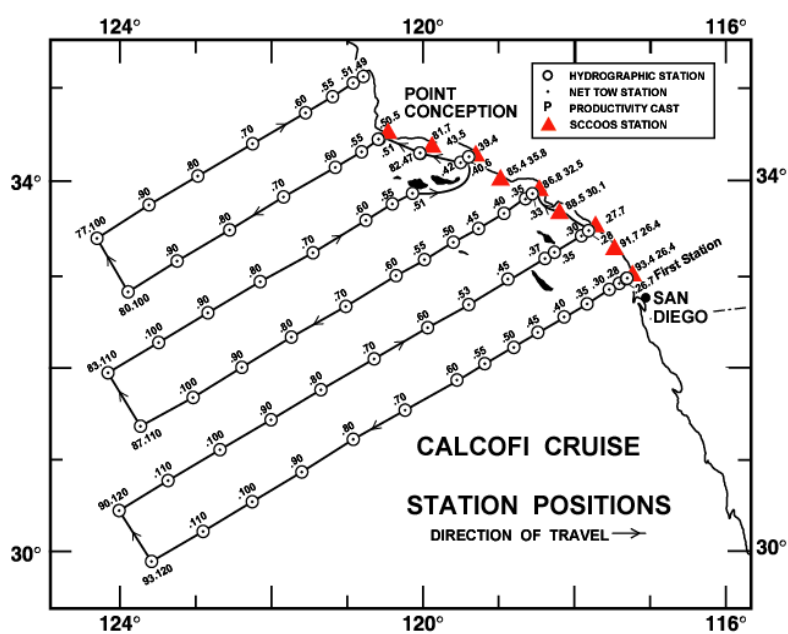

Figure 1. The primary CalCOFI station plan since 1984. Spring cruises during the sardine spawning season have extended north to San Francisco since 2003. In the original station plan, transects extended north of California and south along Baja California. The inshore SCCOOS stations were added in 2004, funded by the Southern California Coastal Ocean Observing System. 
maintained since 1988 off Monterey by the Monterey Bay Aquarium Research Institute. The Pacific Coast Ocean Observing System (PaCOOS) has supported the development of several further transects that can be sampled monthly over a single day off Bodega Bay and Humboldt, California. CalCOFI undoubtedly influenced the design of the marine resources monitoring, assessment, and prediction (MARMAP (Marine Resources Monitoring, Assessment, and Prediction)) surveys established by NMFS/NOAA (National Oceanic and Atmospheric Administration off the US east coast in 1977, which conducted oceanographic, zooplankton and ichthyoplankton sampling over an extensive grid in the Mid-Atlantic Bight. However, there are extensive zooplankton and ichthyoplankton monitoring programs elsewhere in the world, such as those in the waters around Japan [2 and 3], where the influence of CalCOFI is difficult to determine. It is notable that these ocean observation time series based on spatially extensive sampling grids have been sustained due to their relevance to fisheries as well as to oceanography and climate.

\section{SCIENTIFIC OUTCOMES AND BENEFITS}

In its early years, CalCOFI samples and data were used primarily to examine temporal and spatial patterns of spawning, distribution and abundance for a wide range of ecologically and commercially important taxa, as well as spatio-temporal patterns in physical and chemical oceanographic properties. In addition to many papers in the primary literature, CalCOFI produced 35 atlases, 27 of them before 1980. This is the first phase in describing and understanding an oceanographic environment and its fauna.

As the CalCOFI time series lengthened, it was increasingly used to examine the impacts of climate variability on the California Current system and the physical-biological dynamics underlying climate processes. In a landmark paper, Chelton et al. [4] showed that zooplankton displacement volume, obtained from CalCOFI cruises, responded coherently in the northern and southern California Current to the strong El Nino of 1957-58 (but see [5] and [6] for an alternate explanation). More recently, CalCOFI data were used to assess the impacts of both ENSO (El Niño/Southern Oscillation) and the Pacific Decadal Oscillation (PDO) on key krill species [7] (Fig. 2). CalCOFI time series for salinity, nutrients and chlorophyll, which previously appeared unrelated to ENSO and the PDO, were recently shown to be closely correlated with the second mode of northeast Pacific decadal variability, the North Pacific Gyre Oscillation (NPGO) [8] (Fig. 3). The CalCOFI data set is increasingly used to test models that seek to explore the potential impacts of long-term climate change on the California Current [9]. A full review of CalCOFI's
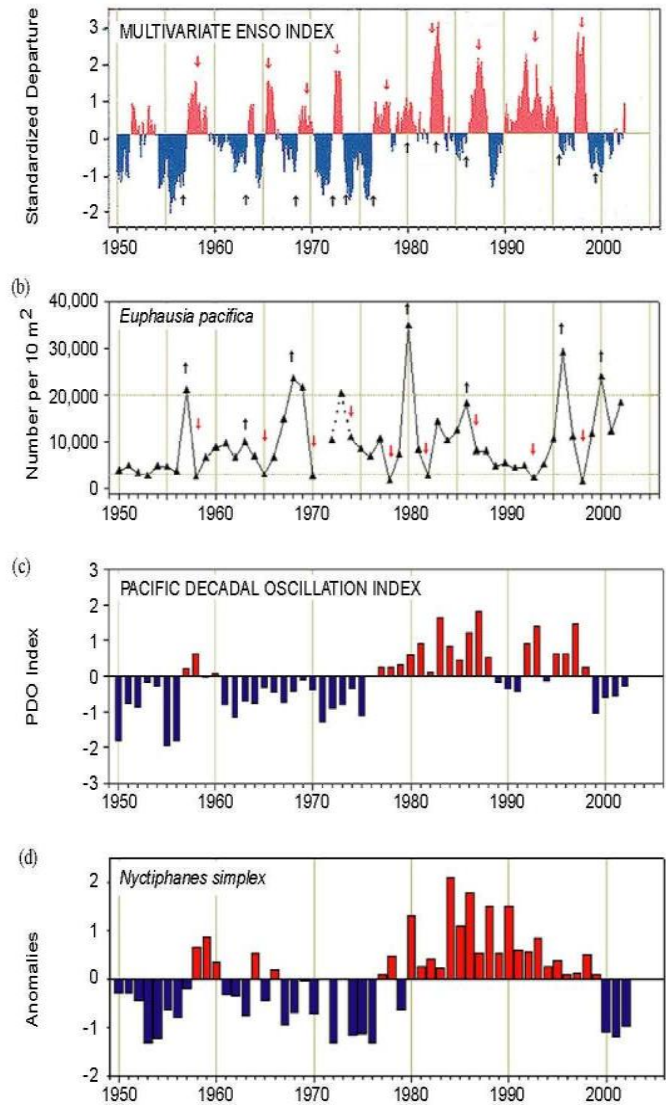

Figure 2. Time series for El Niño-Southern Oscillation (ENSO), the Pacific Decadal Oscillation (PDO) and from CalCOFI, two dominant euphausiid (krill) species, Euphausia Pacifica and Nyctiphanes simplex.

E. Pacifica abundance is best correlated with the ENSO cycle, with peaks during La Niña, whereas the abundance of N. simplex is correlated with the PDO, increasing during warm periods and declining during cool periods. (From Brinton and Townsend 2003.)

contributions to the oceanographic literature is outside the scope of this paper, but good recent reviews include [10] and [11].

A key reason for the long-term viability of the CalCOFI program has been the use of the egg and larval data to estimate the spawning stock biomass of northern anchovy Pacific sardine, made possible by development of the daily egg production method [12], [13] and [14].. More recently the egg surveys have been improved through development of the Continuous Underway Fish Egg Sampler [15], which provides realtime, high-resolution information on egg distributions, which can be used to enhance sampling strategy.

Although the oceanographic mechanisms responsible for massive changes in the sardine population are still not well understood, several hypotheses have recently been advanced to explain patterns in sardine recruitment and production, based largely on analysis 


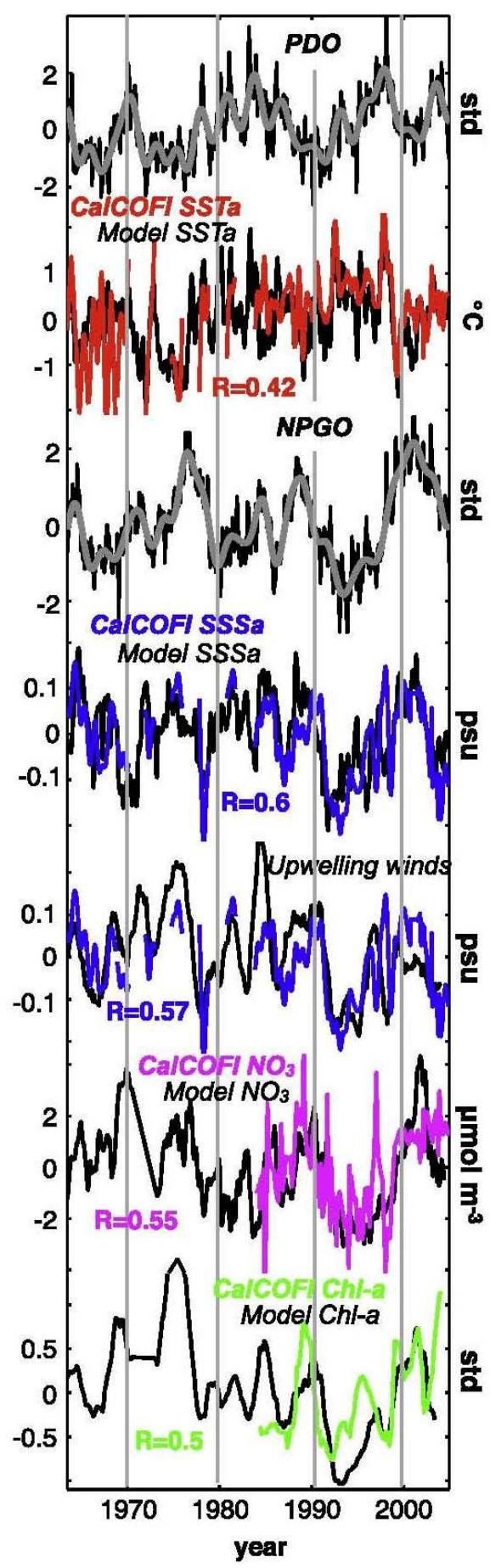

Figure 3. Time series of the Pacific Decadal Oscillation (PDO), North Pacific Gyre Oscillation (NPGO) and sea surface temperature (SST), sea surface salinity (SSS), upwelling winds, nitrate at 150 $m$, and chlorophyll with model values in black and colored values from CalCOFI. (From Di Lorenzo et al 2008.)

of the CalCOFI data set. Enhanced survival and production of sardine larvae has been observed in offshore eddies, a regular and notable feature of the southern California Current [16] and [17]. Sardine recruitment and production are correlated with offshore wind-stress curl-driven upwelling but not coastal upwelling [18]. Offshore upwelling is also correlated with nutricline depth and chlorophyll concentration, providing a potential mechanism in terms of enhanced feeding and growth to explain the relationship with sardine production. Japanese researchers proposed an alternative hypothesis based on the temperaturedependent growth of larval and juvenile sardine and anchovy, favoring anchovy off Japan during warm temperature regimes and sardine during cool periods, to explain the commonly-observed alternation in their relative success. Although this work has largely focused on these species in the northwest Pacific [19] and [20], similar mechanisms have been proposed for the California Current [21]. These hypotheses are not mutually exclusive and need to be tested in the field.

The CalCOFI program enumerates the abundance of some 400 taxa of fish larvae, making it possible to examine the population dynamics of the diverse fish fauna of the California Current, including commercial and non-commercial species and fishes from pelagic and midwater, coastal and offshore assemblages and with several biogeographic affinities. Many of these species, such as the myctophids, are highly abundant and important prey species to a wide range of fish, squid, and marine mammal predators. Some midwater fishes have been designated sentinel species and are critical for ecosystem modeling, although they are generally difficult to sample and obtain a time-series for, except as ichthyoplankton.

This unique data set allowed Hsieh et al. [22] to show that fishing increases the variability of fished species abundance, an impact of commercial exploitation that had been previously suspected but not clearly demonstrated. Analysis of this rich data set has shown that the biological data from the region, unlike the physical data, are inherently nonlinear, thereby amplifying physical environmental variability [23]. This has considerable ramifications for modeling and predicting population responses to climate variability. The abundance of many of the dominant fish species in the southern California Current assemblage is significantly correlated with climate indices, particularly the Pacific Decadal Oscillation. The abundance of diel-migratory midwater species has largely increased following the 1977-78 regime shift [24] and [25].

\section{THE FUTURE}

The need for ecosystem-based management (EBM) of fisheries and marine ecosystems is widely accepted today, but its implementation is less clear. EBM incorporates not only multiple species within the ecosystem but also the influence of ocean conditions 
on system productivity. One example where a proxy for ocean conditions has been incorporated into management is the Pacific sardine, which is managed using a single-species stock assessment model with a temperature parameter (the three-year running mean temperature off Scripps' pier) as a proxy, indicating whether the California Current is in a warm or cool phase. There is value in simplicity, but it is anomalous that no use is made of the extensive CalCOFI data set for this purpose. Likewise, CalCOFI data have not been used to manage invertebrate fisheries, which now rival finfish fisheries in terms of ex-vessel landings in California [26]. The distribution of lobster phyllosoma and Dungeness crab megalopae in CalCOFI samples may help address this gap.

A workshop of west coast oceanographers and fisheries scientists in 2006 concluded that key gaps in current research were the role of climate and mid-trophic levels (e.g. krill and small pelagics) in the California Current [27]. Upwelling ecosystems have been described as 'wasp-waisted,' [28], meaning there are relatively few species at mid-trophic levels (e.g. the sardine, anchovy and one or two dominant krill species), which prey upon a diverse assemblage of phytoplankton and zooplankton, and support diverse predator populations: seabirds, threatened and endangered marine mammals, and piscivorous fishes. As a result, the dynamics of higher trophic level species in these ecosystems may be closely linked to the variability of these key mid-trophic level species. It was recognized that models that incorporated such organisms must be based on an understanding of their behavior in relation to predators, prey, and hydrographic features, and that this understanding was not presently available. Such models are a critical step in predicting the impacts of climate variability and climate change on mid- and higher trophic levels.

To obtain the observations that must underlie such models, multi-frequency acoustic systems are now used on CalCOFI surveys to obtain data on mid-trophic levels. Underway data on temperature, salinity, chlorophyll $a$ and zooplankton-sized particles will soon be collected through the water column to $200 \mathrm{~m}$ with a Moving Vessel Profiler. The distributions of krill, small pelagics, and micronekton from the acoustics can then be analyzed in relation to both fine-scale hydrography and the distribution of their prey (zooplankton particles) and predators (seabirds and marine mammals). To improve the temporal resolution of regional data, an ancillary program now deploys gliders along the CalCOFI lines off Pt Conception and San Diego and funds are being sought to establish moorings off Pt Conception and in the SCB (Southern California Bight).

Funds are also being sought to support this expanded suite of observations, in particular to manage the increasingly complex data streams, and to develop coupled biophysical models to make best use of new data streams and implement EBM. Web-based access to the combined physical and ichthyoplankton CalCOFI data sets is now being implemented, but incorporating the diverse ancillary data sets into the database remains a significant challenge. These data sets range from seabird and mammal observations to phytoplankton and zooplankton species counts to carbon and iron chemistry measurements.

CalCOFI physical data have been successfully assimilated into ROMS (Regional Ocean Modeling System) physical models of the California Current [29] (Di Lorenzo et al. 2003). However, although coupled biophysical models of the northern California Current have now been developed [30] and [31] (Batchelder et al. 2002, Powell et al. 2006), such models have not yet been extended to the southern California Current to incorporate CalCOFI observations. However, coupled biophysical models that would include this region are now funded as part of the NSF-supported California Current Ecosystem Long-Term Ecological Research and NSF/NOAA-funded CAMEO (Comparative Analysis of Marine Ecosystems Organization) programs.

CalCOFI funding has fluctuated considerably over the years. However, the suite of ocean observations has evolved with changes in observing technologies and scientific interests. The greatest opportunity for expansion of CalCOFI lies in the growing need to understand and predict the impacts of climate change and implement EBM. These goals can only be achieved with an expanded ocean observation system that has a long enough time series to detect trends and significant anomalies related to environmental and anthropogenic forcing.

\section{REFERENCES}

1. Hooff, R. C., Peterson, W. T. (2006) Copepod biodiversity as an indicator of changes in ocean and climate conditions of the northern California current ecosystem. Limnology and Oceanography 51, 26072620

2. Hirota, Y., Hasegawa, S. (1999) The zooplankton biomass in the Sea of Japan. Fisheries Oceanography 8, 274-283.

3. Watanabe, H., Kawaguchi, K. (2003) Decadal change in abundance of surface migratory myctophid fishes in the Kuroshio region from 1957 to 1994. Fisheries Oceanography 12, 100-111.

4. Chelton, D. B., Bernal, P. A., McGowan, J. A. (1982) Large-scale interannual physical and biological interaction in the California Current. Journal of Marine Research 40, 95-112. 
5. Lavaniegos, B. E., Ohman, M. D. (2003) Long term changes in pelagic tunicates of the California Current. Deep-Sea Research II 50, 2493-2518.

6. Lavaniegos, B. E., Ohman, M. D. (2007) Coherence of long-term variations of zooplankton in two sectors of the California Current System. Progress in Oceanography 75, 42-69.

7. Brinton, E., Townsend, A. (2003) Decadal variability in abundances of the dominant euphausiid species in southern sectors of the California Current. Deep-Sea Res II 50, 2449-2472.

8. Di Lorenzo, E., et al. (2008) North Pacific Gyre Oscillation links ocean climate and ecosystem change. Geophysical Research Letters 35, L08607.

9. Di Lorenzo, E., Miller, A. J., Schneider, N., McWilliams, J. C. (2005) The warming of the California Current system: dynamics and ecosystem implications. J Phys Ocean 35, 336-362.

10. Ohman, M. D. Venrick, E. L. (2003) CalCOFI in a changing ocean. Oceanography 16, 76-85.

11. Checkley, D. M., Barth, J. A. (2009) Patterns and process in the California Current. Progress in Oceanography 83, 49-64.

12. Parker, K. (1980) A direct method for estimating northern anchovy Engraulis mordax, spawning biomass. Fishery Bulletin 78, 541-544.

13. Lasker, R. (1985) An egg production method for estimating spawning biomass of pelagic fish: application to the northern anchovy, Engraulis mordax. NOAA Technical Report NMFS 36.

14. Lo, N. C. H. (1985) Egg production of the central stock of northern anchovy, Engraulis mordax, 1951-1982. Fishery Bulletin 83, 137-150.

15. Checkley, D. M., Jr., Ortner, P. R., Settle, L. R., Cummings, S. R. (1997) A continuous, underway fish egg sampler. Fisheries Oceanography 6, 58-73.

16. Logerwell, E., Lavaniegos, B., Smith, P. E. (2001) Spatially-explicit bioenergetics of Pacific sardine in the Southern Californian Bight: are mesoscale eddies areas of exceptional prerecruit production? Progress in Oceanography 49, 391-406.

17. Logerwell, E. A., Smith, P. E. (2001) Mesoscale eddies and survival of late stage Pacific sardine (Sardinops sagax) larvae. Fisheries Oceanography 10, 13-25.
18. Rykaczewski, R. R., Checkley, D. M. (2008) Influence of ocean winds on the pelagic ecosystem in upwelling regions. Proc National Academy of Sciences 105, 1965-1970.

19. Takahashi, M. Watanabe, Y. (2004) Growth ratedependent recruitment of Japanese anchovy Engraulis japonicus in the Kuroshio-Oyashio transitional waters. Mar Ecol Prog Ser 266, 227-238.

20. Takasuka, A., Oozeki, Y., Aoki, I. (2007) Optimal growth temperature hypothesis: why do anchovy flourish and sardine collapse or vice versa under the same ocean regime? Canadian Journal of Fisheries and Aquatic Sciences 64, 768-776.

21. Takasuka, A., Oozeki, Y., Kubota, H., Lluch-Cota, S. E. (2008) Contrasting spawning temperature optima: Why are anchovy and sardine regime shifts synchronous across the North Pacific? Progress in Oceanography 77, 225-232.

22. Hsieh, C., Reiss, C. S., Hunter, J. R., Beddington, J. R., May, R. M., Sugihara, G. (2006) Fishing elevates variability in the abundance of exploited species. Nature 443, 859-862.

23. Hsieh, C.-H., Ohman, M. D. (2006) Biological responses to environmental forcing: the linear tracking window hypothesis. Ecology 87, 1932-1938.

24. Hsieh, C.-H., Kim, H. J., Watson, W., Di Lorenzo, E., Sugihara, G. (2009) Climate-driven changes in abundance and distribution of larvae of oceanic fishes in the southern California region. Global Change Biology. doi:10.1111/j.1365-2486.2009.01875.x.

25. Hsieh, C.-H., et al. (2005) A comparison of long-term trends and variability in populations of larvae of exploited and unexploited fishes in the southern California region: a community approach. Progress in Oceanography 67, 160-185.

26. Rogers-Bennett, L. (Ed.) 2002. Review of some California fisheries for 2001: Market squid, sea urchin, Dungeness crab, lobster, prawn, abalone, groundfishes, swordfish and sharks, coastal pelagic finfishes, ocean salmon, nearshore live-fishes, Pacific herring, white seabass, and kelp. CalCOFI Reports 43, 13-30.

27. Barth, J., et al. (2006) Climate Variability and Change in the California Current Ecosystem: A Plan for Research to Inform Management. Report of a workshop held in La Jolla, CA. 
28. Cury, P., et al. (2000) Small pelagics in upwelling systems: patterns of interaction and structural changes in "wasp-waist" ecosystems. ICES Journal of Marine Science 57, 603-618.

29. Di Lorenzo, E. (2003) Seasonal dynamics of the surface circulation in the Southern California Current system. Deep-Sea Research II 50, 2371-2388.

30. Powell, T., Lewis, C., Curchitser, E. N., Haidvogel, D. B., Hermann, A. J., Dobbins, E. L. (2006) Results from a three-dimensional, nested biological-physical model of the California Current System and comparisons with statistics from satellite imagery. Journal of Geophysical Research 111, doi:10.1029/2004JC002506.

31. Batchelder, H. P., Edwards, C. A., Powell, T. M. (2002) Individual-based models of copepod populations in coastal upwelling regions: implications of physiologically and environmentally influenced diel vertical migration on demographic success and nearshore retention. Progress in Oceanography 53, 307-333 